\title{
Vessel sanitation inspection scores and acute gastroenteritis outbreaks on cruise ships
}

\section{Eilif Dahl}

Department of Occupational Medicine, Norwegian Centre for Maritime and Diving Medicine, Haukeland University Hospital, Bergen, Norway

In the early 1970s, when Caribbean cruising was in its infancy, there were few rules and regulations regarding vessel sanitation. Midnight buffets were served on deck in subtropical temperatures for hours without any cooling systems, and hand washing units for food handlers were few and far between. Not surprisingly, some ships had massive outbreaks of acute gastroenteritis (AGE) from "food poisoning". The cruise companies downplayed the risks, but the United States Public Health Services (USPHS) and the United States Centers for Disease Control and Prevention (CDC) reacted and started a comprehensive Vessel Sanitation Programme (VSP) which all ships of a certain size visiting United States ports after 1975 had to follow [1].

The VSP was not popular. The extensive unannounced audits covered all areas of the ship and compliance with all the new rules meant a lot of extra work, especially for the ships' management, engineers, housekeepers, food handlers and medical staff. The score system, from 0 to 100 points, let a ship with 86 points pass, while 100 was a perfect score [1]. In the first 3 months after the inspections were started in 1975, not one of 60 inspected ships passed the CDC inspection [2]. However, despite some initial reluctance from the ships, over the next 10 years compliance improved, the average VSP scores increased and the number of AGE outbreaks declined despite steadily more ships. Through the first half of $1985,70 \%$ of the vessels were passing regularly [2].

In 1986 CDC lost their VSP funding and the programme was terminated [1]. Ship employees were pleased and looked forward to easier workdays with less vigorous sanitation routines. But just a few weeks after routine inspections stopped, three highly publicised outbreaks of AGE that affected more than 1200 passengers hit the headlines [2]. Cruise industry, public, political and media pressures resulted in CDC reinstating an updated VSP in 1987 - from then on entirely funded by the cruise industry [1]. This time cruise companies and employees were far more positive; more sanitation measures were accepted to reduce the risk of disruptive outbreaks.

Vessel Sanitation Programme's comprehensive food safety and environmental sanitation inspections clearly worked against foodborne outbreaks: During 1990 to 2000, VSP inspection scores increased steadily, the proportion of vessels failing sanitation inspections decreased (from $27.3 \%$ to $7.4 \%$ ) and the incidence of outbreaks of diarrheal disease fell (from 6.2 to 3.7 outbreaks per 1000 cruises) [3].

After 2002, however, the incidence rates of AGE outbreak again increased - despite consistently high VSP scores. Explosive vomiting was a more distinct symptom than diarrhoea, and the main cause was no longer bacterial, but viral. As opposed to bacterial food poisoning, the very contagious norovirus is associated with person-to-person and environmental transmission of disease [4]. Infected passengers caused most outbreaks by bringing the virus aboard and they spread it by vomiting or defecating in the public facilities or simply touching surfaces with unclean hands. A stricter and even more comprehensive VSP was started - with increased focus on proper hand-washing, disinfection of surfaces, quick isolation of symptomatic patients, close surveillance of patient contacts and systems to avoid getting the virus aboard [1].

A United States study of AGE on cruise ships between 2008 and 2014 showed that norovirus caused $92 \%$ of the outbreaks. The number and severity of AGE outbreaks varied during the study period, but were lower than rates reported during 2001-2004 [5].

In this issue of "International Maritime Health", Dr. Christopher James Taylor presents a study based on USPH information from the period 2012-2017 [6]. The VSP inspection scores throughout the industry were consistently high but for vacation planners who want to find a ship with a low risk of an AGE outbreak, they are useless: The study 
shows that the VSP inspection scores had no prognostic value regarding future AGE outbreaks on cruise ships [6].

Although VSP inspection scores are not correlated with AGE outbreaks caused by norovirus, scores and specific categories of violations on cruise ships are clearly associated with common-source foodborne illness [4]. Constantly high inspection scores show that a ship takes hygiene seriously and is working hard to maintain a high level of sanitation. On the other hand, those who just want to be on "the cleanest ship afloat" might consider cruising on a vessel that has recently failed a VSP inspection - because the crewmembers on that ship are expecting a new VSP inspection fairly soon and are doing their very best to keep their ship spic-and-span to avoid a second VSP failure.

Compliance with the VSP has improved the hygienic conditions aboard cruise ships tremendously over the years and who knows how many health disasters it has prevented. Although time-consuming, work-intensive, expensive and at times utterly frustrating, the VSP has undoubtedly been a blessing for the cruise industry. It is viewed as an international model of cruise ship sanitation and collaborates with multiple global partners to improve ship safety $[7,8]$. But, as the VSP scores have no predictive value and adequate vessel hygiene does not guarantee prevention of AGE outbreaks by norovirus, further measures must be sought and evaluated to identify those ships at greatest risk of future outbreaks. The main focus must be on ways to interrupt and preferably prevent person-to-person and fomite transmission aboard $[9,10]$.

Health care providers offering pre-travel services should emphasize the importance of rigorous hand sanitation aboard and actively encourage use of ship-board greetings that do not involve touching of potentially contaminated palms or fingertips [11]. They should also strongly discourage self-medication for AGE aboard cruise ships. But it is currently rather common for travel clinics to supply cruise passengers with a short course of broad-spectrum antibiotics to take if they experience any gastrointestinal symptoms during their voyage. For AGE caused by norovirus, a self-limiting condition, antibiotics are of no value, while isolation must be done quickly to prevent further transmission. Tentative self-medication causes contagious patients to continue to use - and contaminate - public areas while waiting for expected improvement. Necessary isolation is thus delayed. Instead, travel clinics should instruct prospective passen- gers to never try to treat themselves but to promptly contact and to cooperate closely with the ship's infirmary staff at the slightest abdominal upset.

\section{CONFLICT OF INTEREST}

The author has no commercial, financial or other relationships related to the subject of this article. He has worked as ship's doctor and medical consultant for many cruise companies.

\section{REFERENCES}

1. U.S. Department of Health and Human Services U.S. Public Health Service, Centers for Disease Control and Prevention/ National Center for Environmental Health. Vessel Sanitation Program 2018 Operations Manual. . https://www.cdc.gov/nceh/vsp/docs/ vsp_operations_manual_2018-508.pdf.

2. Korcok M. Sick at sea: outbreaks prompt reinstatement of cruise ship inspections. CMAJ. 1987; 136(12): 1298-1300, indexed in Pubmed: 3034392.

3. Cramer EH, Gu DX, Durbin RE. Diarrheal disease on cruise ships, 1990-2000: the impact of environmental health programs. Am J Prev Med. 2003; 24(3): 227-233, indexed in Pubmed: 12657340.

4. Cramer EH, Blanton CJ, Blanton LH, et al. Epidemiology of gastroenteritis on cruise ships, 2001-2004. Am J Prev Med. 2006; 30(3): 252-257, doi: 10.1016/j.amepre.2005.10.027, indexed in Pubmed: 16476642.

5. Freeland AL, Vaughan GH, Banerjee SN. Acute Gastroenteritis on Cruise Ships - United States, 2008-2014. MMWR Morb Mortal Wkly Rep. 2016; 65(1): 1-5, doi: 10.15585/mmwr.mm6501a1, indexed in Pubmed: 26766396.

6. Taylor CJ. Gastroenteritis outbreaks on cruise ships: are sanitation inspection scores a true index of risk? Int Marit Health 2018; 69(4): 225-232; doi: 10.5603/IMH.2018.0037.

7. Mouchtouri VA, Nichols G, Rachiotis G, et al. SHIPSAN partnership. State of the art: public health and passenger ships. Int Marit Health. 2010; 61(2): 49-98, indexed in Pubmed: 21154293.

8. Ames J. Update on the CDC Vessel Sanitation Program. NCEH/ATSDR Board of Scientific Counselors Meeting (Record of Proceedings), Atlanta, Georgia, June 3-4. 2015.

9. Chimonas MAR, Vaughan GH, Andre Z, et al. Passenger behaviors associated with norovirus infection on board a cruise ship: Alaska, May to June 2004. J Travel Med. 2008; 15(3): 177-183, doi: 10.1111/j. 1708-8305.2008.00200.x, indexed in Pubmed: 18494695.

10. Mouchtouri VA, Verykouki E, Zamfir D, et al. Gastroenteritis outbreaks on cruise ships: contributing factors and thresholds for early outbreak detection. Euro Surveill. 2017; 22(45), doi: 10.2807/15607917.ES.2017.22.45.16-00576, indexed in Pubmed: 29162205.

11. Dahl E. Cruise tap versus handshake: using common sense to reduce hand contamination and germ transmission on cruise ships. Int Marit Health. 2016; 67(4): 181-184, doi: 10.5603/IMH.2016.0034, indexed in Pubmed: 28009396. 